\title{
Mental Models of Verifiability in Voting
}

\author{
Maina M. Olembo, Steffen Bartsch, and Melanie Volkamer \\ Technische Universität Darmstadt / Center for Advanced Security Research \\ Darmstadt, Germany \\ Name.Surname@cased.de
}

\begin{abstract}
In order for voters to verify their votes, they have to carry out additional steps besides selecting a candidate and submitting their vote. In previous work, voters have been found to be confused about the concept of and motivation for verifiability in electronic voting when confronted with it. In order to better communicate verifiability to voters, we identify mental models of verifiability in voting using a questionnaire distributed online in Germany. The identified mental models are, Trusting, No Knowledge, Observer, Personal Involvement and Matching models. Within the same survey, we identify terms that can be used in place of 'verify' as well as security-relevant metaphors known to the voters that can be used to communicate verifiability.
\end{abstract}

Keywords: Mental Models, Verifiability, Internet Voting, Voting

\section{Introduction}

Internet voting continues to generate great interest, with a recent survey in Germany [1] finding that more than $50 \%$ of eligible voters would cast their vote over the Internet for federal elections. Despite this interest, security experts have expressed concern over the integrity of Internet voting, for example Simons and Jones 2. Verifiability offers some assurance of the integrity of votes cast in an election - both in traditional as well as in Internet-based elections. Voters however, have to carry out additional steps to verify the integrity of their individual votes (and if they are interested, all votes) cast in an election. While in traditional paper-based elections voters are not confronted with verifying (e.g. assuming that poll workers do not ask voters to remain behind to verify that votes are properly tallied), they are in Internet based elections: In the vote casting interface, there might be a button to click on to verify, a link to the bulletin board, or voters get a receipt to verify later on.

Sherman et al. 3 and Volk et al. 4 found that voters are confused about the concept of and motivation for verifiability. Similarly, Schneider et al. [5] report that voters expressed confusion over use of the term 'receipt'. This confusion and lack of understanding and motivation in voters shows the need to investigate mental models of verifiability in voting to base future communication of 
verifiability on these models. It also shows the need to use a different term or phrase for 'verifying'. In this work we seek to identify mental models of and terms for verifiability. We define mental models as 'voters' knowledge, beliefs and attitudes of verifiability as they cast votes in postal voting and paper-based voting at the polling station'. We use a questionnaire distributed online.

The mental models are identified as Trusting, No Knowledg $\oint^{1}$ Observer, Personal Involvement and Matching models. The most appropriate term identified is check. While we concentrate in this work on Internet-based verifiable voting systems, our findings are relevant to verifiable e-voting systems in general, as the mental models identified are based on traditional voting systems.

The remainder of this paper is structured as follows: we give background information in Section 2 on verifiability and voting procedures in Germany, followed by a discussion of related work in usable verifiable electronic voting in Section 3 We present the methodology of our study in Section 4, the results in Section 5 , and discuss the implications of our findings and future work in Section 6.

\section{Background}

Background information is provided on the verifiability definitions, and the voting processes in Germany are introduced briefly as the questionnaire was distributed to German citizens.

Verifiability definitions. Verifiability addresses the following three aspects: Cast as intended - the voter can verify that his vote has been cast as he intended; Stored as cast - the voter can verify that his vote is stored for tabulation as he cast it; and Tallied as stored - anybody can verify that all votes have been tallied as they were stored ${ }^{2}$

Voting processes in Germany. In Germany, voters can cast paper votes at the polling station, or register for absentee voting and use postal voting. Postal voting has been provided in Germany since 1956 to cater for voters who for one reason or another cannot cast their vote in person at a polling station [7. Furthermore, postal voting has continued to experience increasing use, with $21.4 \%$ of voters using postal voting for the 2009 federal elections [7. Another special provision for German elections is that ordinary voters and interested parties are allowed to remain at the polling station, including the location where postal votes are stored and tallied, to observe election processes during set up, voting and the tallying of votes, as long as they do not disrupt the proceedings 8 .

${ }^{1}$ By no knowledge, we refer to participants who were uncertain how to verify votes in postal voting, and paper voting, despite the fact that voters are allowed to observe voting processes in Germany.

${ }^{2}$ While these are the definitions selected for this work, other definitions of verifiability exist in the literature, for example [6]. 


\section{Related Work}

Different techniques have been applied to identify mental models in voting. Schneider et al. 5] carried out a series of focus group sessions to evaluate, among other issues, voters' understanding of security mechanisms in an early version of Prêt à Voter. Storer et al. 9] also interacted with participants in focus groups and additionally used videotaped scenarios to study voters' attitudes towards a pollsterless remote voting system. Campbell and Byrne [10] investigated voters' mental model of straight party voting using an online survey, while Yao and Murphy [11, used a paper-based survey to evaluate voters' perceptions of, and their intention to use, telephone and web-based interfaces of remote electronic voting systems.

Since few studies have been carried out to specifically investigate voters' mental models in voting, we also considered literature in the field of computer security. Raja et al. [12] carried out a lab study of Vista Basic firewall, and a firewall prototype that included contextual information of the current and future network states. Almuhimedi et al. 13. used a survey and a lab study in web certificate management.

Using semi-structured interviews, Raja et al. [14 explored participants' knowledge, requirements, perceptions and misconceptions about personal firewalls. Friedman et al. [15] tested users' conceptions of web security using semi-structured interviews that included a drawing task. Ho et al. [16] interviewed caretakers of wireless home computer networks to understand how they deployed and secured the networks. Wash [17 conducted interviews to understand users' folk models of attackers and security technologies. Dourish et al. 18] carried out semi-structured interviews to identify people's perceptions of security.

Mental models of computer security [19] and privacy and security [20] were identified from literature and tested in a two-card sorting experiment [21], 22], [23] involving experts and non-experts. Bravo-Lillo et al. 24] used scenarios in open-ended interviews to evaluate mental models of computer security warnings.

We see a variety of approaches used to identify mental models in voting and in computer security. In this study, we distributed a questionnaire online to participants, integrating scenario diagrams to elicit terms for verifiability.

\section{Methodology}

The research questions and study instruments, participant recruitment, data analysis, and ethical considerations for the study, are described in this section. All study materials were written in English and translated into German. The data collected was translated into English for analysis and reporting. The translations were verified for accuracy by the authors. Additionally, the data collected on terms for verifiability was analyzed in German since future work will investigate their use in Germany. 


\subsection{Research Questions and Study Instruments}

The research question is: What mental models do participants have of verifiability in postal voting and paper voting at the polling station? This was explored by asking participants the following questions addressing different aspects of verifiability:

- how they could tell that their individual postal vote was not modified or removed on its way to the town hall and into the ballot box $\left(Q 1_{\text {postal }}\right)$.

- how they could tell that their postal or paper vote was not modified or removed from the ballot box, $\left(Q 22_{\text {postal }}\right)$ and $\left(Q 22_{\text {paper }}\right)$.

- how they could tell that their postal or paper vote was included in the final tally, $\left(Q 3_{\text {postal }}\right)$ and $\left(Q 3_{\text {paper }}\right)$.

- how they could tell that all postal or paper votes were included in the final tally, $\left(Q 4_{\text {postal }}\right)$ and $\left(Q 4_{\text {paper }}\right)$.

These questions were derived from the stored as cast and tallied as stored verifiability definitions. Note the problem with the first verifiability step: cast as intended, i.e. making sure that the vote is not modified before being sent is not a concern in paper-based elections and thus is not addressed here. The questionnaire is shown in Table 5 in the Appendix. Participants first answered demographic questions which acted as screening questions to allow exclusion of data from participants who did not meet the requirements (see Subsection 4.2). Scenario diagrams, shown in Figures 1 to 6, were developed by a professional graphic designer and used to obtain terms for verifiability.

\subsection{Participant Recruitment}

Participants were recruited to form a convenience sample [25]. We did not seek participants representative of the German population, rather we aimed to carry out an exploratory study to identify research questions for further investigation on mental models of verifiability. We therefore do not generalize our findings to the entire population. Invitation emails were first sent to an initial pool of participants known to the authors, then a second email, containing a URL and password to access the questionnaire, was sent to those participants who expressed interest in the study. This approach has been shown to improve response rates [26]. These participants were requested to forward the email to other persons whom they thought would be interested in participating, in a snowballing technique [27. Participants represented different age groups and professional backgrounds including retired workers. Eligible participants were German citizens, used the Internet, and were over the age of 18 (in order to be eligible to vote in elections). Participants were not offered compensation, instead we asked those interested to provide their email addresse ${ }^{3}$ to receive information on the results of the survey [28].

Out of 55 participants who filled out the questionnaire online, 11 did not complete it. We therefore consider data from 44 participants. There were 31

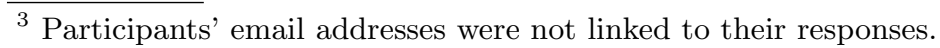


male and 13 female respondents. Ten participants had been educated up to high school level, and 34 had university education. Forty participants reported using the Internet everyday, while four used it every two to three days. Data on participants' age ranges and level of computer proficiency (measured by asking participants whether they install computer programs on their computers) are shown in Table 1 and Table 2, respectively.

\begin{tabular}{lc}
\hline Age & Number \\
\hline $19-34$ & 16 \\
$35-44$ & 9 \\
$45-54$ & 8 \\
$55-64$ & 8 \\
$65+$ & 3 \\
\hline
\end{tabular}

Table 1: Demographic Data Age

\begin{tabular}{|c|c|}
\hline \multicolumn{2}{|c|}{ Computer Proficiency Number } \\
\hline Install on their own & 20 \\
\hline Need help to install & 10 \\
\hline Others ask them for help & 13 \\
\hline Do not install & 1 \\
\hline
\end{tabular}

\subsection{Data Analysis}

Responses were analyzed using content analysis and open coding [29. In content analysis, participants' responses are analyzed and categorized using explicit rules. Open coding was used in order to obtain emerging themes from participants' responses, rather than beginning the data analysis with pre-selected themes. If one participant mentioned several concepts, each was coded under an appropriate theme. We used spreadsheets to assign the different concepts and themes to each question. For example, a response such as No knowledge, only trust in regulated procedures and sanctions and mutual control during the count by the people present, as well as to this day minor known cases of abuse was identified to have the following relevant concepts: No Knowledge, Trust in processes, and Observers present. These concepts were grouped into themes, which form the mental models. One participant could have expressed several concepts that would be classified under different mental models. The concepts identified in this example were then categorized under No Knowledge, Trusting and Observer models.

Two researchers independently reviewed a subset of the data and identified concepts and emerging themes from participants' responses. A Cohen's Kappa of 0.65 was obtained. Any value above 0.60 indicates acceptable inter-rater reliability 29. The remaining responses were then analyzed. In coding the data, one question was analyzed in its entirety before researchers moved on to analyze the next question. This process was repeated until all participants' responses to all questions had been analyzed, and emerging themes identified.

We analyzed participants' responses based on the meaning of phrases and the response as a whole, first identifying concepts and themes and then the mental 

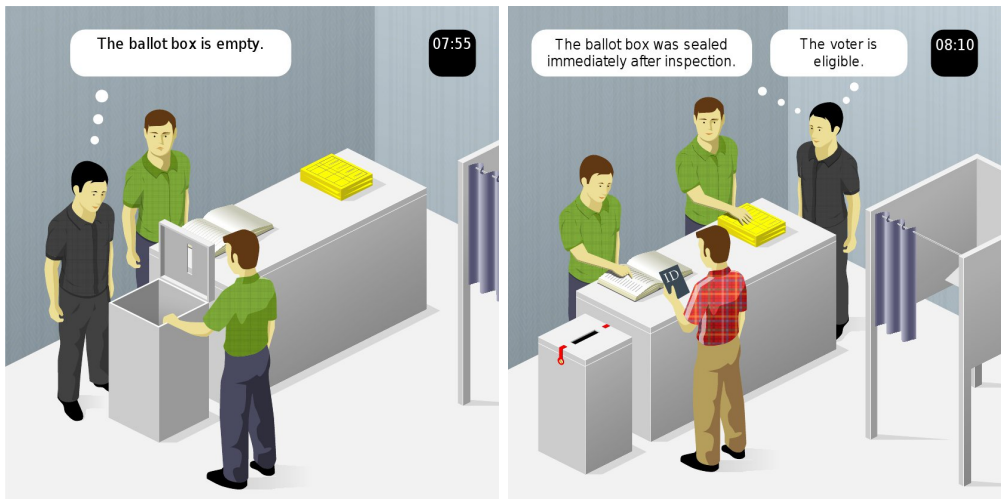

Fig. 1: The Ballot Box is Empty

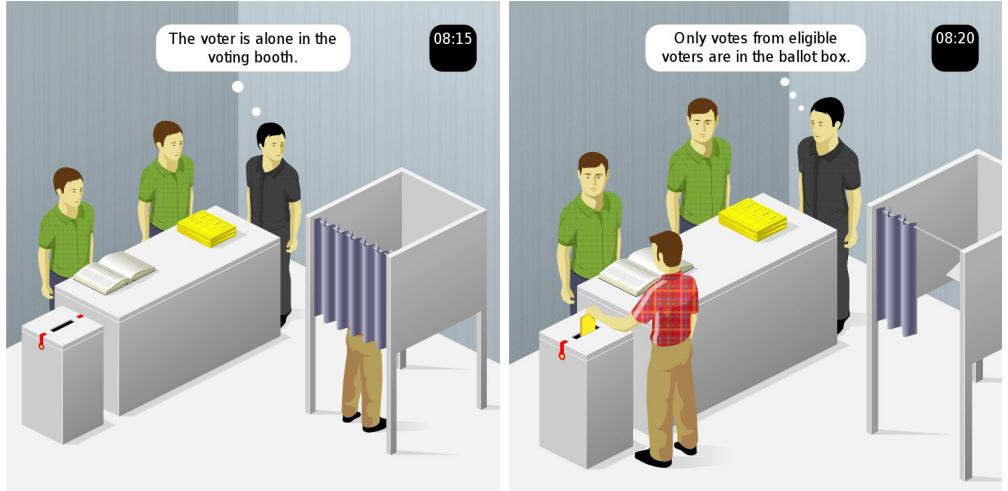

Fig. 3: The Voter goes alone into Fig. 4: Eligible Voters' Votes are the Voting Booth in the Ballot Box
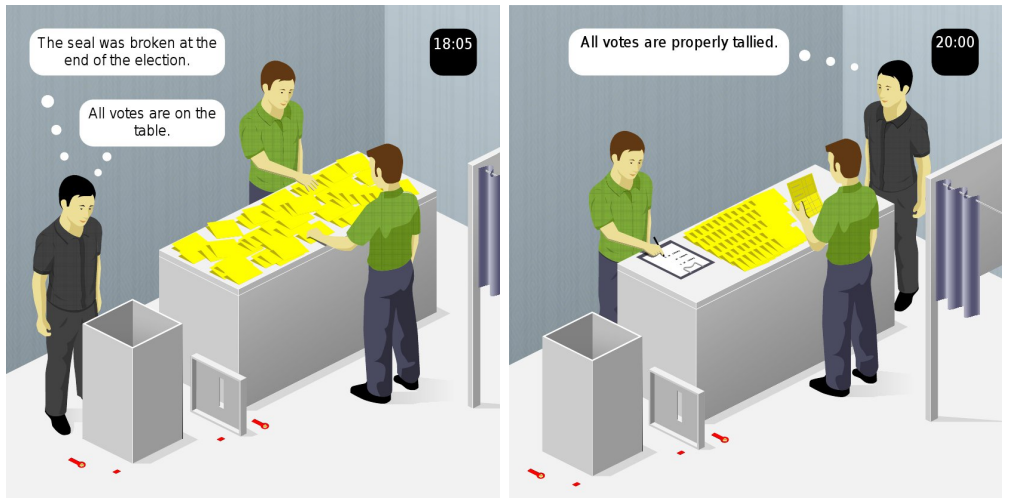

Fig. 5: The Seal is Broken and Fig. 6: All Votes are Properly the Ballot Box is Empty Tallied 
models. We observed that two themes, specifically, trusting and no knowledge, were identified in participants' responses to $\left(Q 1_{\text {postal }}\right)$. The remaining themes were identified while analyzing responses from $\left(Q 2_{\text {postal }}\right)$ to $\left(Q 4_{\text {postal }}\right)$ and from $\left(Q 2_{\text {paper }}\right)$ to $\left(Q 4_{\text {paper }}\right)$. Concepts within the themes primarily remained the same for the different questions, though there was a slight change, reflecting the differing situations presented in the questions, that is, moving from vote storage to tallying of votes. As such, it is likely that theoretical saturation [30] was attained at this point and unlikely that introducing more participants would reveal any new themes.

\subsection{Ethical Considerations}

Ethical requirements for research involving human participants are provided by an ethics commission at the university ${ }^{4}$. The relevant ethical requirements regarding participant consent and data privacy were met. Participants were first informed about the purpose of the study, after which they could decide whether or not to proceed to the questionnaire. They were informed that the purpose of the study was to better understand preferences for Internet voting based on use of traditional voting systems, to avoid causing bias by referring to integrity in voting or verifiability. In order to meet the data privacy requirement, a privacy statement was provided on the questionnaire, assuring participants that their data would only be collected for research purposes, their identity would not be linked to their responses, and their data would not be passed on to third parties. Furthermore, participants' data was only handled by researchers involved in the project.

\section{Results}

We present the results of this work, first discussing the different mental models of verifiability in voting that have been identified, and metaphors and terms that can be used in reference to verifiability processes.

\subsection{Mental Models}

A number of mental models were identified from participants' responses. Specifically, Trusting, No Knowledge, Observer, Personal Involvement, and Matching models were identified. Examples of the concepts identified and accompanying mental models are shown in Table 4 in the Appendix. As mentioned above, themes overlapped with respect to the concepts, for instance, for the Trusting and Observer models, in the case where participants trust that observers will notice manipulations.

We first discuss each of the mental models and then propose metaphors and terms participants used while answering the questions and which might be used

\footnotetext{
${ }^{4}$ http://www.intern.tu-darmstadt.de/gremien/ethikkommisson/index.en.jsp
} 
to improve the communication of verifiability. The mental models are reported in this section based on the number of concepts identified; those with a high number of concepts are listed first.

Trusting Model: Participants' responses indicated that they had blind trust, trust in persons, or trust in processes for integrity of their individual votes and all votes cast in an election. Another new concept was trust (no option), with the participant stating 'I have to trust in it'. As participants moved from question $Q 1_{\text {postal }}$ to question $Q 4_{\text {postal }}$, new concepts emerged such as: trust in observers in $Q 2_{\text {postal }}$, trust the count in $Q 3_{\text {postal }}$, and trust in the public count of votes in $Q 4_{\text {postal }}$, as an example, one participant stated '... one also has to trust in the count'. The concept of the envelope used in postal voting being sealed was observed, with a participant stating '...I trust that the sealed envelope is only opened to count my vote'. Similarly, new concepts were observed across the responses in $Q 2_{\text {paper }}$ through to $Q 4_{\text {paper }}$, for example, trust in the public count of votes.

No Knowledge Model: Participants' responses indicated they were either not sure how to ascertain the integrity of their individual vote and other voters' votes, or they considered that there was no way for this to be done. Participants stated, for example, 'I don't know', 'You can never know', and 'Not at all'. We also noted that many concepts in this model were linked to other concepts from different mental models, for example, one participant responded 'I don't know; I trust', and another, 'I don't know; I trust that the procedure of the election is properly monitored'.

Observer Model: Participants referred mostly to observers being present during the vote casting process and the tallying of votes. One participant referred to the presence of observers which assured him of the integrity of his individual vote in $Q 1_{\text {postal }}$ and a few referred to the presence of observers in $Q 2_{\text {postal }}$ to $Q 4_{\text {postal }}$. As an example, one participant said 'Therefore election observers are permitted...', in response to $Q 3_{\text {postal }}$. In paper voting, participants expressed assurance of how their vote was handled because observers were present. Since different election workers were present and likely to have different party affiliations, participants also considered them as playing a role in ensuring the integrity of the voting process. Additionally, participants referred to election workers observing each other, and the results being verified by several people. The election workers were referred to more times in response to $Q 2_{\text {paper }}$ to $Q 4_{\text {paper }}$, which could be because participants interact with them more during the voting process, in comparison to postal voting, where voters might never interact with the election workers in person.

Additionally, participants were assured of the integrity of their votes and all votes since they were counted in public. Relevant concepts were observed in $Q 3_{\text {postal }}$ and $Q 4_{\text {postal }}$ with one participant indicating 'Due to the fact that 
the count is done in public...'. Relevant concepts were identified from $Q 2_{\text {paper }}$ to $Q 4_{\text {paper }}$. In the responses given, participants did not specify how the public count could ensure the integrity of individual votes and all votes.

Personal Involvement Model: Participants made reference to being personally involved in the tallying process by observing the tallying of votes in person $\left(Q 4_{\text {postal }}\right)$ with this participant stating 'I can watch the count of the absentee votes...'. Other concepts were submitting the vote personally $\left(Q 2_{\text {paper }}\right)$, observing in person $\left(Q 3_{\text {paper }}\right)$ and participating in the public count $\left(Q 4_{\text {paper }}\right)$.

Matching Model: Participants responses made reference to checking that the final results matched the observed results $\left(Q 4_{\text {postal }}\right)$ and that the number of votes matched the number of participating voters $\left(Q 22_{\text {paper }}\right)$.

\subsection{Further Results}

We identified a number of metaphors from participants' responses, which can be tailored to communicate verifiability. Furthermore, terms that participants use to describe verifiability are reported.

Metaphors: A number of metaphors were identified from participants' responses. The ballot box was referred to as being sealed (in both postal voting and paper voting), and physically protected (in postal voting). The envelope being sealed gave assurance to one participant that any tampering with his postal vote would be detected '...because the envelope would have to be opened and the vote then becomes invalid' $\left(Q 2_{\text {postal }}\right)$.

Terms For Verifiability: Terms were obtained from participants' responses to describe the action of the man in black (Figures 1 to 6). These and accompanying English translations are shown in Table 3 . Some participants used multiple terms to describe the action. Responses that only appeared once are grouped together under 'Other'.

\begin{tabular}{l|l|l}
\hline English translation & German term & Count \\
\hline To observe & beobachten & 18 \\
To check & kontrollieren & 10 \\
To verify & überprüfen & 6 \\
To monitor & überwachen & 5 \\
Other & & 11 \\
\hline
\end{tabular}

Table 3: Terms for Verifiability 


\section{Discussion}

User studies of voters' interaction with verifiable voting systems, for example in 3 and 31, show that voters are confused about the concept of verifiability. In this work, we have identified the mental models of verifiability of German voters to gain insights on how to improve voters' understanding of verifiability. Specifically, we have identified Trusting, No Knowledge, Observer, Personal involvement, and Matching mental models.

Our results indicate that there are gaps in voters' knowledge, beliefs and attitudes towards verifiability in voting as more concepts were identified for the Trusting and No Knowledge mental models. These gaps need to be closed by communicating verifiability. One approach could be to inform voters that the trust-inducing elements present in traditional (paper-based) voting systems, for example, observers, are not the same in Internet voting. The argument could then follow that voters need to personally act as observers, or that they need to carry out extra steps.

Our findings on the mental models can be employed to improve user interfaces for verifiable voting. While one option would be to first identify voters' mental models and then communicate verifiability according to the model(s) that voters have, legal requirements are that all voters receive the same information. Correspondingly, in future work, we will investigate designing an interface that is adequate for several - ideally all - identified mental models. Future work will also consider the effect that this improved communication has on voters checking their votes.

Moreover, the metaphors and terms for verifiability identified in this work will be applied in the improved communication. The identified metaphors, sealed and protected ballot box and sealed envelope, can be exploited to communicate individual verifiability. One option could be in providing a contrast, for example, informing voters that while these aspects are present in postal voting and paperbased voting at the polling station, they are not available in Internet voting, thus prompting the voter to participate in verifiability processes.

Similarly, further research will utilize the German terms that participants used to refer to verifying. While 'observe' is the highest ranking term, we consider that the term 'check' offers more options for use in communicating verifiability to voters. Some sample phrases are 'check the vote preparation process', and 'check the correctness of the counting process'. The appropriateness of these and other phrases will be evaluated in future work.

Since this study targeted German voters, it would be of interest to identify and compare additional mental models in other cultures, as well as to conduct additional quantitative work to determine each mental model's prevalence.

\section{Acknowledgment}

Support for this work was provided by CASED (www.cased.de) and Micromata (www.micromata.de). The authors would like to thank the anonymous reviewers for their helpful insights that helped improve the presentation of this work. 


\section{References}

1. Microsoft: Forsa-Umfrage: Jeder zweite würde online wählen. Digitale Technologien stärken die Demokratie. Bürgerbeteiligung über das Internet fördert Vertrauen in die Politik. http://www.microsoft.com/germany/newsroom/pressemitteilung. mspx?id=533684. (2013) Online; accessed 22 March, 2013.

2. Simons, B., Jones, D.W.: Internet voting in the U.S. Communications of the ACM 55(10) (2012) 68-77

3. Sherman, A.T., Carback, R., Chaum, D., Clark, J., Essex, A., Herrnson, P.S., Mayberry, T., Stefan, P., L., R.R., Shen, E., Sinha, B., Vora, P.: Scantegrity Mock Election at Takoma Park. Electronic Voting 2010 (EVOTE2010) (2010) 45 - 61

4. Karayumak, F., Kauer, M., Olembo, M.M., Volk, T., Volkamer, M.: User Study of the Improved Helios Voting System Interface. In: Socio-Technical Aspects in Security and Trust (STAST), IEEE (2011) $37-44$

5. Schneider, S., Llewellyn, M., Culnane, C., Heather, J., Srinivasan, S., Xia, Z.: Focus Group Views on Prêt à Voter 1.0. In: International Workshop on Requirements Engineering for Electronic Voting Systems. (2011)

6. Langer, L., Schmidt, A., Buchmann, J., Volkamer, M.: A Taxonomy Refining the Security Requirements for Electronic Voting: Analyzing Helios as a Proof of Concept. In: Availability, Reliability, and Security, 2010. ARES'10 International Conference on, IEEE (2010) 475-480

7. Krimmer, R., Volkamer, M.: Bits or Paper? Comparing Remote Electronic Voting to Postal Voting. In Andersen, K., Grönlund, A., Traunmüller, R., Wimmer, M., eds.: Workshop and Poster Proceedings of the Fourth International EGOV Conference. (2005) 225-232

8. Demirel, D., Henning, M., Ryan, P.Y.A., Schneider, S., Volkamer, M.: Feasibility Analysis of Prêt à Voter for German Federal Elections. In: International Conference on e-Voting and Identity. (2011)

9. Storer, T., Little, L., Duncan, I.: An Exploratory Study of Voter Attitudes Towards a Pollsterless Remote Voting System. In Chaum, D., Rivest, R., Ryan, P.Y., eds.: IaVoSS Workshop on Trustworthy Elections (WOTE 06) Pre-Proceedings. (2006) $77-86$

10. Campbell, B.A., Byrne, M.D.: Straight-Party Voting: What Do Voters Think? IEEE Transactions on Information Forensics and Security 4(4) (2009) $718-728$

11. Yao, Y., Murphy, L.: Remote Electronic Voting Systems: An Exploration of Voters' Perceptions and Intention to Use. European Journal of Information Systems 16(2) (2007) 106-120

12. Raja, F., Hawkey, K., Beznosov, K.: Revealing Hidden Context: Improving Mental Models of Personal Firewall Users. In: Proceedings of the 5th Symposium on Usable Privacy and Security. SOUPS '09 (2009)

13. Almuhimedi, H., Bhan, A., Mohindra, D., Sunshine, J.S.: Toward Web Browsers that Make or Break Trust. In: Proceedings of the Sixth Symposium on Usable Privacy and Security. SOUPS '08 (2008)

14. Raja, F., Hawkey, K., Jaferian, P., Beznosov, K., Booth, K.S.: It's Too Complicated, So I turned It Off!: Expectations, Perceptions, and Misconceptions of Personal Firewalls. In: Proceedings of the 3rd ACM Workshop on Assurable and Usable Security Configuration. SafeConfig '10 (2010) 53-62

15. Friedman, B., Hurley, D., Howe, D.C., Felten, E., Nissenbaum, H.: Users' Conceptions of Web Security: A Comparative Study. In: Extended Abstracts on Human Factors in Computing Systems. CHI EA '02, ACM (2002) 746-747 
16. Ho, J.T., Dearman, D., Truong, K.N.: Improving Users' Security Choices on Home Wireless Networks. In: Symposium of Usable Privacy and Security. SOUPS '10 (2010)

17. Wash, R.: Folk Models of Home Computer Security. In: Proceedings of the Sixth Symposium on Usable Privacy and Security. SOUPS '10 (2010)

18. Dourish, P., Grinter, B., Delgado de la Flor, J., Joseph, M.: Security in the wild: User Strategies for Managing Security as an Everyday, Practical Problem. Personal and Ubiquitious Computing 8(6) (2004) 391-401

19. Camp, L.J.: Mental Models of Computer Security. In: Proceedings of Financial Cryptography. Lecture Notes in Computer Science, Springer-Verlag (Berlin) (2004)

20. Camp, L.: Mental Models of Privacy and Security. Technology and Society Magazine, IEEE 28(3) (2009) 37-46

21. Asgharpour, F., Liu, D., Camp, L.J.: Mental Models of Computer Security Risks. In: Workshop on the Economics of Information Security. (2007)

22. Liu, D., Asgharpour, F., Camp, L.J.: Risk Communication in Security Using Mental Models. In: Usable Security. (2008)

23. Camp, J., Asgharpour, F., Liu, D.: Risk Communication in Computer Security Using Mental Models. In: Workshop on the Economics of Information Security. WEIS '07 (2007)

24. Bravo-Lillo, C., Cranor, L.F., Downs, J.S., Komanduri, S.: Bridging the Gap in Computer Security Warnings: A Mental Model Approach. IEEE Security and Privacy 9(2) (2011) 18-26

25. Charmaz, K.: Constructing Grounded Theory: A Practical Guide through Qualitative Analysis. 1st edn. Sage Publications Limited (2006)

26. Andrews, D., Nonnecke, B., Preece, J.: Conducting Research on the Internet: Online Survey Design, Development and Implementation Guidelines. International Journal of Human-Computer Interaction 16(2) (2003) 185 - 210

27. Oppenheim, A.N.: Questionnaire Design, Interviewing and Attitude Measurement. Continuum (2000)

28. Wright, K.B.: Researching Internet-based Populations: Advantages and Disadvantages of Online Survey Research, Online Questionnaire Authoring Software Packages, and Web Survey Services. Journal of Computer-Mediated Communication $10(2005)$

29. Lazar, J., Feng, J.H., Hochheiser, H.: Research Methods in Human-Computer Interaction. John Wiley and Sons (2010)

30. Guest, G., Bunce, A., Johnson, L.: How many interviews are enough? an experiment with data saturation and variability. Field methods 18(1) (2006) 59-82

31. Karayumak, F., Michaela, K., Maina, O., Melanie, V.: Usability Analysis of Helios - An Open Source Verifiable Remote Electronic Voting System. In: Proceedings of the 2011 USENIX Electronic Voting Technology Workshop/Workshop on Trustworthy Elections, USENIX (2011) 


\section{A Relevant Study Data}

\begin{tabular}{ll}
\hline Mental Model & Sample of Concepts in Model \\
\hline & Trust(Blind) \\
& Trust(Processes) \\
& Trust(Employees) \\
& Trust(Postal service) \\
& Trust(Sealed envelope) \\
& Trust(Public count of votes) \\
Trusting & Trust(Observers) \\
& Don't know \\
& No way \\
No Knowledge & Published results match observed ones \\
& Number of voters match number of votes \\
Matching & Observers \\
& Different election workers \\
Observer & Public count of votes \\
&
\end{tabular}

Table 4: Some Identified Concepts Grouped Under Mental Models 


\begin{tabular}{|c|c|}
\hline SECTION & QUESTIONS \\
\hline \multirow{5}{*}{ Demographics } & $\begin{array}{l}\text { Please select your age range. } \\
{[18 \text { and under, } 19-34,35-44,45-54,55-64 \text {, over } 65]}\end{array}$ \\
\hline & $\begin{array}{l}\text { What is your gender? } \\
\text { [Male, Female] }\end{array}$ \\
\hline & $\begin{array}{l}\text { What is your highest level of education? } \\
{[\text { High school or less, Some college, Bachelor's degree, Master's }} \\
\text { degree, } \mathrm{PhD}]\end{array}$ \\
\hline & $\begin{array}{l}\text { How often do you use the Internet? } \\
\text { [Every day, Every two or three days, Once a week, Once every } \\
\text { two weeks, Once a month] }\end{array}$ \\
\hline & $\begin{array}{l}\text { Which of the following statements is true in most cases? } \\
\text { [I need help to install programs on my computer, I install com- } \\
\text { puter programs on my computer, Other people ask me to help } \\
\text { them install programs on their computers, I do not install pro- } \\
\text { grams on my computer] }\end{array}$ \\
\hline \multirow{3}{*}{ Mental Model (Paper Voting) } & $\begin{array}{l}\text { How can you tell that the paper vote you cast at the polling } \\
\text { station was not modified or removed from the ballot box? }\end{array}$ \\
\hline & $\begin{array}{l}\text { How can you tell that the paper vote you cast at the polling } \\
\text { station was included in the final tally, that is, as it was stored } \\
\text { in the ballot box? }\end{array}$ \\
\hline & $\begin{array}{l}\text { How can you tell that the paper votes cast at the polling stations } \\
\text { are included in the final tally, as they were stored in the ballot } \\
\text { box? }\end{array}$ \\
\hline \multirow{4}{*}{ Mental Model (Postal Voting) } & $\begin{array}{l}\text { How can you tell that your postal vote was not modified or } \\
\text { removed on its way to the town hall and into the ballot box? }\end{array}$ \\
\hline & $\begin{array}{l}\text { How can you tell that your postal vote was not modified or } \\
\text { removed from the ballot box? }\end{array}$ \\
\hline & $\begin{array}{l}\text { How can you tell that your postal vote was included in the final } \\
\text { tally, that is, as it was stored in the ballot box? }\end{array}$ \\
\hline & $\begin{array}{l}\text { How can you tell that all postal votes are included in the final } \\
\text { tally, as they were stored in the ballot box? }\end{array}$ \\
\hline Verifiability Terms & $\begin{array}{l}\text { Kindly give one word or phrase to describe what the man in } \\
\text { black (in reference to the scenario diagrams) is doing }\end{array}$ \\
\hline
\end{tabular}

